\title{
Wearables the Next Big Thing in Smart Healthcare
}

\author{
Sakshi Mobar ${ }^{1}$ \\ Market Research \& Consulting, NEC Technologies India Private Ltd., Noida, India ${ }^{1}$
}

\begin{abstract}
India is expected to rank amongst the top three healthcare markets in the world in terms of incremental growth by 2020, contributing 2.5 per cent of GDP in the 12th Five Year Plan. With the doctor-to-patient ratio as per the Medical Council of India, being at 1:1,674, well below the WHO's recommendation of 1:1,000 the need to adopt smart wearables is a must which allow the people of India the responsibility to self-check their health indicators [1]. This paper focuses on the smart healthcare concept and how smart healthcare is incomplete without the adoption of wearables. A brief glimpse is also made between the wearables available in India and those available globally to cater to the health needs of the consumers. Lastly, recommendations have been made of how Smart Healthcare can be implanted in India keeping the focus on wearables and keeping it in sync with the trending initiatives of the Indian Government.
\end{abstract}

Keywords: Wearables, Smart Healthcare, Make in India, Digital India.

\section{INTRODUCTION TO INDIAN HEALTHCARE}

The Healthcare Industry has witnessed to become one of India's largest sectors - both in terms of revenue with an expected growth of USD 280 billion in size by 2020 and employment with a doubled workforce of 7.4 million by 2022 [1]. Factors contributing to boost healthcare services demand in the near future are increasing income levels, ageing population, growing health awareness and changing perception towards preventive healthcare.

Indian healthcare delivery system majorly constitutes - public and private delivery channels. The Government, i.e. public healthcare system comprises limited secondary and tertiary care institutions in major cities and focuses on providing basic healthcare facilities in the form of primary healthcare centre's (PHCs) in rural areas. The private sector provides majority of secondary, tertiary and quaternary care health center's with a major focus in metros, tier I and tier II cities.

Though, the Healthcare system in India boasts of its highly skilled medical professionals and its cost competitive attitude, what needs to be achieved is a progress towards Smart Healthcare.

\section{SMART HEALTHCARE}

Smart Healthcare comprises of smart systems in the healthcare and fitness domain that interact with their environment through internet to cater to the complex situations. The infrastructure support for such a system is an integration of many smart systems accessible to end users. Smart Healthcare to an individual means reduced medical errors, accurate tests, limited doctor visits and overall more holistic care, resulting in reduced healthcare costs and time. For healthcare professionals, it means information at their fingertips to assist them better diagnose patients.

A normal individual can be given the strength and personal accountability to monitor and diagnose one's own health by using devices such as wearables - which can be connected to mobile apps to generate alert notifications. The Smart Healthcare in the time to come might be dominated by these wearables which will contribute to be an effective, time saving health indicator.

\section{WEARABLES}

Wearables are compact and smart electronic devices that can be incorporated by a person in various forms.

TABLE I

\begin{tabular}{|l|l|}
\hline Forms & Example \\
\hline Ingestible - located within the body & Smart Pills \\
\hline Mounted - attached to the body & Smart Watch, Smart Clothing \\
\hline Intimate - worn such that it is indistinguishable & Contact Lens (in progress) \\
\hline
\end{tabular}




\section{UGC Approved Journal}

The architecture of a wearable device mainly comprises of - a sensor, user interface and an internet network. Connectivity on the device is enabled through Bluetooth, internet or mobile networks, depending on the endapplication. These devices collect, process and transmit data in real-time.

The information gathered through wearable devices can be used to generate actionable insights by the Physician or can be accessed by the Family for monitoring purposes. Some of the popular wearable devices in Healthcare are Smart Watch, Fitness Band, and Smart Clothing to name a few.

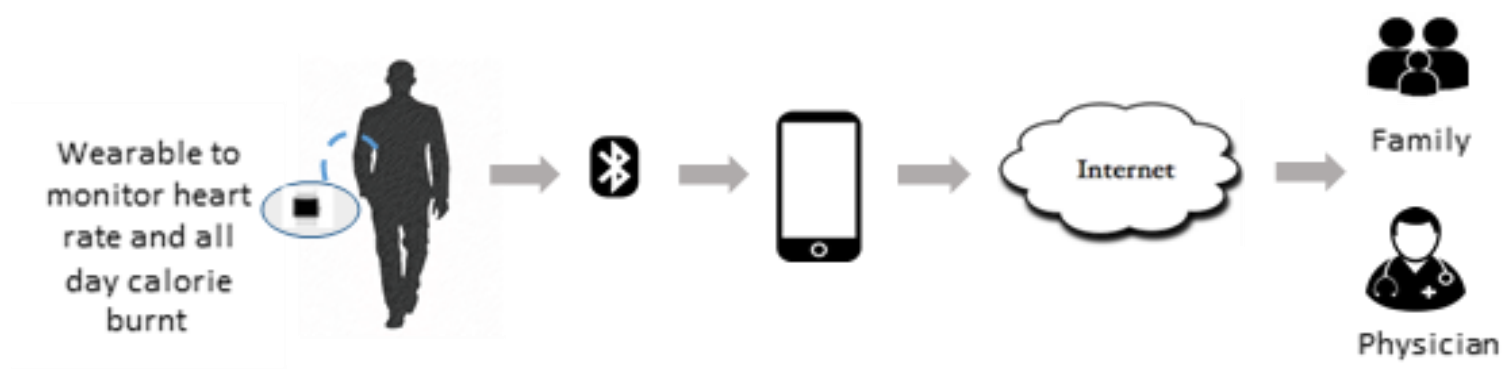

Fig. 1 Wearable Device Architecture

\section{WEARABLE MARKET IN INDIA}

Indian wearable devices market is rapidly gaining momentum as it provides a convenient health tracking mechanism to the users. The year 2016 witnessed, the Indian wearable market shipment of around 2.5 million units. However, the total wearable shipment in Q4 2016 totalled 0.675 million units which included both smart wearables as well as basic wearables [2].

Wearable have become immensely popular in the past one year with more players expected to launch products in coming years. Investments are being made for the continuous development of products to provide better value to users and the market is expected to evolve on all parameters such as price, product features and target segments.

However, the leading player in the wearable devices market for Q4 2016 happens to be a Health start up firm GOQii with a $15.5 \%$ market share in terms of shipments, closely followed by Xiaomi with a $13.2 \%$ market share, while Fitbit accounted for $7.9 \%$ market share during the same quarter. The access to a personal trainer has been the unique selling point of the GOQii [2].

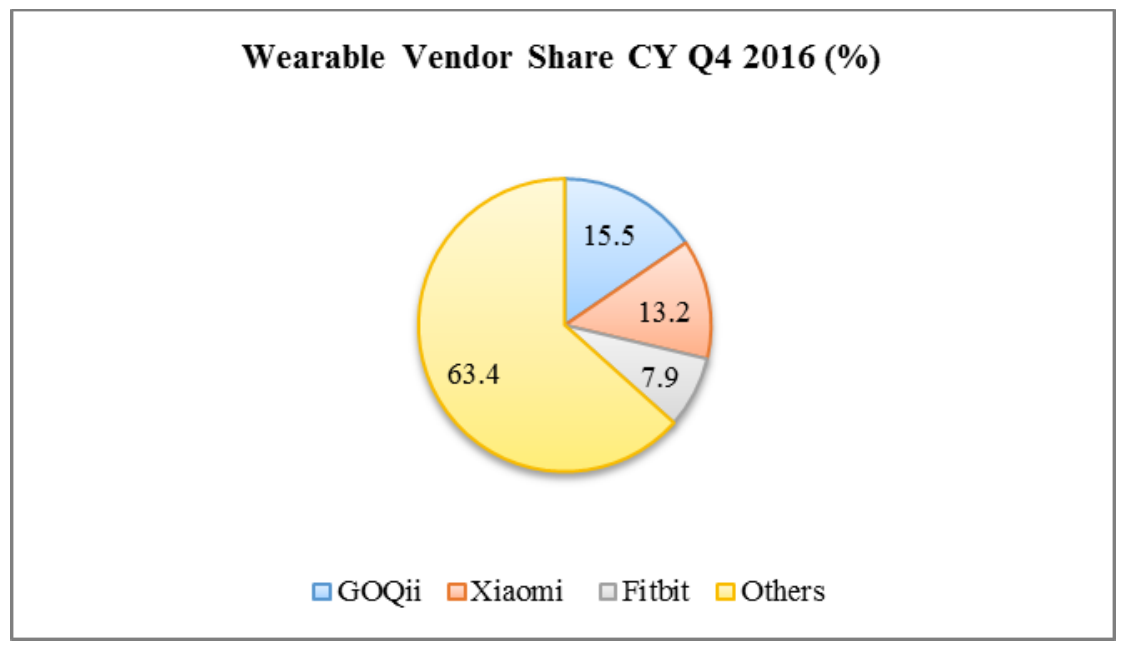

Fig. 2 Wearable Vendor Share

\section{BRIEF OVERVIEW OF WEARABLES AVAILABLE IN INDIA}

The Indian market is predominantly a basic wearable market with fitness trackers and cheaper smart watches. Though brands like Samsung and Apple do offer premium smart watches to the customers who are willing to shell out a hefty sum. 


\section{A. Smart watches}

A smartwatch, can usually perform multiple functions similar to a smartphone.

Once connected to a smartphone it displays notifications, alerts, and messages, allows to browse the internet, play music and media and much more. In addition to these health and fitness can also be tracked by knowing the calories burned, steps taken, heart rate and sleep monitoring to name a few.

\section{B. Fitness bands}

The core objective of these bands is tracking your health statistics. The daily activity in terms of steps and calories burned through movement can be measured. Goals can be created to track how active one wants to be and they will provide a rough guide as to how successful one has been.

\section{GLIMPSE OF WEARABLES AVAILABLE AROUND THE WORLD}

The market for wearables is not just limited to smart watches and fitness bands rather it offers a pool of options to cater to the healthcare needs of the patient or the healthcare organizations.

The below mentioned wearables provides an un-exhaustive glimpse of the wearables available globally.

\section{A. Smart Clothing}

This concept began in 2015 and is yet to be a mainstream activity. However, companies are innovating with this unique concept of connected garments or technology embedded into their fabric. Offering much more than strapping gadgets to the wrists, faces, ears and feet, smart clothing can constantly track our heart rate, monitor our emotions, temperature, respiratory rate and blood oxygen saturation. Popular examples in this category are Smart Socks, Smart Sleeve, Smart Baby Hat and Smart Shirt among others.

\section{B. Smart Pill}

This concept is currently focused on two primary functions: wireless patient monitoring and diagnostic imaging. The system mainly comprises of a smartphone, a sensor patch and a pill. The sensor is coated with metals magnesium and copper and then encapsulated in the pill. The consumption of these metals is not harmful as they exist in multi-vitamin supplements and well as are part of our natural diet. The sensor is activated by electrolytes within the body after the pill is swallowed. A signal is transmitted from the pill to a patch worn by the user and sends the data via Bluetooth to the physician or family member's smartphone.

\section{Back Therapy Wearable}

This is designed for people facing lower back health issues. It consists of a small device that can be attached to the person's back. The double pair of smart sensors are able to store data in real time which can then be accessed through the companion application on the smartphones or tablets, run on Bluetooth smart technology. The App further tracks performance and progress, checks the precision and accuracy of moves, and allows sharing the results with the therapist.

\section{Knee Brace Wearable}

This is one of the new healthcare wearables in the knee brace category. It is embedded with the market required sensors that allow for smart keeping of information. It is Bluetooth compatible that can be accessed through an optional companion app supported on an iOS. The app allows to control therapy and track progress. The battery provides pain relief for over 40 hours before having to be charged again.

\section{E. Health Track Wearable}

This is a new technology for healthcare professionals to be able to keep tabs on the key information of their patients. This technology consists of a biosensor that is reusable and it is embedded in a patch that can be disposed of. Heart rate, breathing, temperature, steps taken, and body position in case if a person has fallen can be detected. Bluetooth capability allows access to real time data received through a biosensor.

F. Glucose Monitoring Wearable

A new state of the art glucose monitoring system for people suffering from diabetes. It is a sensor which reads glucose information from the sensor that is placed on the back of the upper arm for 14 days. It thus eliminates the need for the finger prick system used for glucose testing. It is a companion app and smartphone accessible product which allows a doctor to read the patient details. The app also provides information about the food to be taken and ways to control diabetes through exercise and proper dieting. 
With such diverse options of wearables available globally, India for sure has the potential and the capability with its skilled workforce to produce similar options for its citizens.

\section{STEPS AHEAD FOR INDIA}

India under the leadership of its Prime Minister, Mr Narendra Modi envisages to implement programmes/policies that are not limited to - Make in India, Digital India and National Health Policy-2017. A collaborative effort of these keeping in mind the healthcare domain would result in an effective deployment of "Smart Healthcare ".

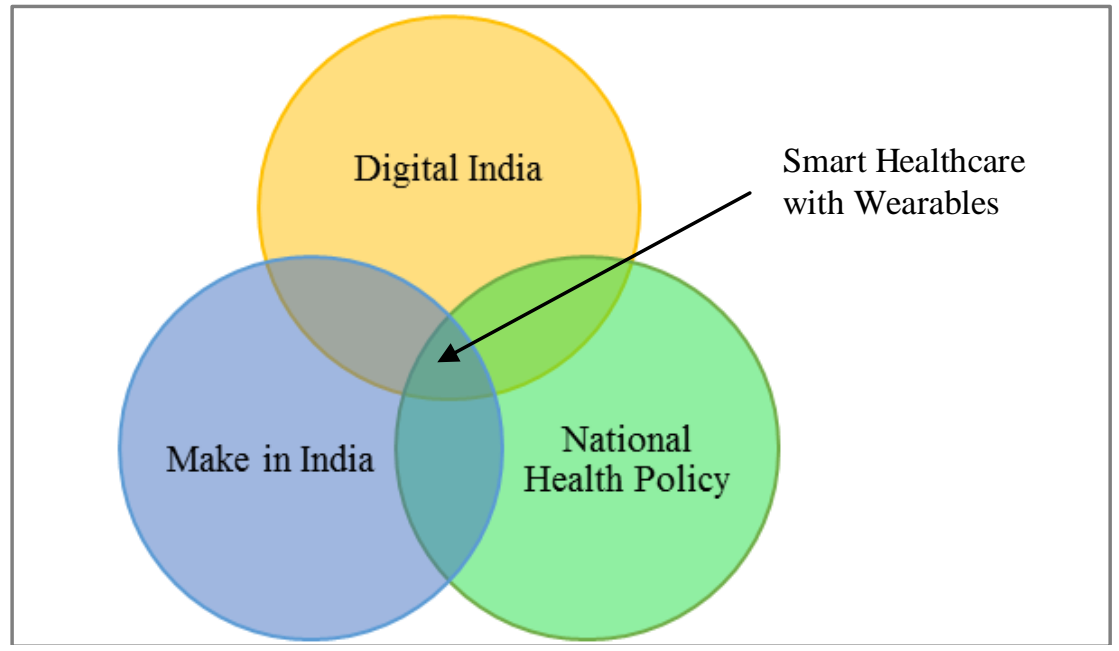

Fig. 2 Collaboration leading to Smart Healthcare

\section{A. Digital India}

Digital India is a programme with a vision to transform India into a digitally empowered country. The inclination of Indians towards digitalization can be observed by the increase in the smartphone subscribers from 270 million in 2016 to an estimated 890 million smartphone subscribers in 2022 [7]. This huge growth in the number of smartphone subscribers offers great scope for these wearables. Wearables, though a unique device of its own have limited processing ability however when coupled with a smartphone they tend to offer greater functionality. Being connected to smartphones allows the collected health stats to be synced with the phone which can further be analysed to provide health insights.

\section{B. Make in India}

The aim of this initiative is to transform India into a global design and manufacturing hub. Players have been importing wearable into Indian market, however with "Make in India" initiative many players including Timex, Intex and Flex, have shown keen interest to manufacture the devices locally. Now, with India having a strong pool of skilled health workforce, a collaboration with wearable/medical devices manufacturing companies to devise such wearables can be an optimum opportunity. The focus here should be to move from the basic wearables to smart wearables such as the ones available globally.

\section{National Health Policy-2017}

One of the aims of this policy is prevention of diseases and promotion of good health through cross sectoral action and access to technologies to provide universal access to healthcare. Since India is majorly impacted by diabetes, cardio vascular and respiratory diseases, the Government can initiate to focus on wearables that can allow prevention of these diseases and help patients to lower the cost of treatment via self-monitoring.

\section{CONCLUSION}

The emergence of smart wearables is the key to smart healthcare. By empowering the citizens of India with digital technologies and providing them the strength to self-monitor themselves will testify the proverb "prevention is better than cure." Hence, if we can use technology to gain health and cut down on medical expenses, it is a step in the right direction. 
UGC Approved Journal

IARJSET

ISO 3297:2007 Certified

Vol. 4, Issue 7, July 2017

\section{ACKNOWLEDGMENT}

I would like to thank my organization for giving me the platform to publish my paper on the trending concept of wearables in Healthcare.

\section{REFERENCES}

[1] “Healthcare Industry in India,” IBEF, June 2017, Available: https://www.ibef.org/download/Healthcare-June-2017.pdf

[2] "Press Release,” IDC, March 2017, Available: https://www.idc.com/getdoc.jsp?containerId=prAP42423317

[3] "The Five best smart watches for health and fitness," smartwatches.org, August 2015, Available: http://smartwatches.org/learn/the-5-bestsmartwatches-for-health-and-fitness/

[4] "The best smart clothing: From biometric shirts to contactless payment jackets,"wareable.com, June 2017, Available: https://www.wareable.com/smart-clothing/best-smart-clothing

[5] Proteus, 2017, Available: http://www.proteus.com/how-it-works/

[6] "Wearables in Healthcare," wearable technologies, April 2015, Available: https://www.wearable-technologies.com/2015/04/wearables-inhealthcare/

[7] Ericsson Mobilty Report, June 2017,Available: https://www.wearable-technologies.com/2015/04/wearables-in-healthcare/

[8] "Indians with diabetes may number 120 million in20 years," Indian Express, April 2017,Available: http://www.newindianexpress.com/nation/2017/apr/06/indians-with-diabetes-may-number-120-million-in-20-years-indian-institute-of-publichealth-1590602.html

[9] “National Health Policy,” Press Information Bureau, March 2017, Available: http://www.newindianexpress.com/nation/2017/apr/06/indianswith-diabetes-may-number-120-million-in-20-years-indian-institute-of-public-health-1590602.html

[10] Make in India-About us , Available: http://www.makeinindia.com/about

[11] Digital India, July 2017, Available: http://digitalindia.gov.in/content/introduction

\section{BIOGRAPHY}

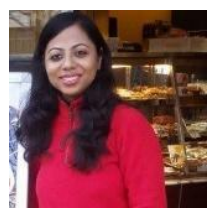

Sakshi Mobar has an industry experience of about 3 years in the Research and Consulting domain across the industry verticals - IT, ITES and Healthcare. Sakshi holds a Bachelor's degree in Electrical \& Electronics and a Master's degree in Marketing \& Finance. 